\title{
Spectrofluorometric Determination of Protoporphyrin IX in Cells Using Acridine as Internal Standard
}

\author{
Ho-Suk Lee, Jee-Bum Lee, ${ }^{\dagger}$ Sook Jung Yun, Jee Young Choi, Jonghoon $\mathrm{Oh}$, and Hyoung-Ryun Park \\ Department of Chemistry, Chomam National University, Gwangin 500-757, Korea. "E-mail: hrpark@chonamackr \\ 'Department of Dermatology, Chonnam National University Medical School, Gwangin 501-757, Korea \\ Received April 10, 2006
}

Key Words : Spectrofluorometric determination, 5 - $\Lambda$ minolevulinic acid, Protoporphyrin IX, $\Lambda$ cridine, Internal standard

Photodynamic therapy (PDT) has been used for diagnosis and treatment of patients with various malignant tumors, including cancers of the skin, gastrointestinal tract, lung and uterus. ' Recently, PDT with using 5-aminolevulinic acid (ALA) for cutaneous diseases has been attracted considerable attentions, because skin is easily accessible to light and drugs. Since ALA was used as a pre-drug of the photosensitizer in PDT research by Kenedy et al. in $1990,{ }^{2}$ a number of ALA ester derivatives have been synthesized and applied to PDT. ALA and its ester derivatives are precursors of protoporphyrin IX (PpIX) in the biosynthetic pathway of heme. ${ }^{3+}$ They are normally biosynthesized in vivo from glycine and succinyl-coenzyme $\mathrm{A}$ in mitochondria and then converted into the actual photosensitizer, PpIX. PpLX produced through the heme biosynthetic pathway emits fluorescence strongly and photobleaches rapidly under production of singlet oxygen. ${ }^{6}$ The amount of ALA-induced porphyrins can be generally determined by measuring the fluorescence under various experimental conditions. Most papers have reported that the amount of fluorescence was determined by the measurement of fluorescence intensity at the maximum emission wavelength. ${ }^{1,7-9}$

Fluorescence spectra were measured by single-beam operation in which a sample is examined to determine the amount of light emitted at a given wavelength. Unstable light source and uneven intensities can cause the false peaks in the spectrum. Equally serious is the variation of the sensitivity of the photomultiplier tubes with regard to wavelength. ${ }^{10}$ Moreover, the analytical method for the determination of the fluorescence intensity at a particular wavelength is less sensitive than that of fluorescence spectrum area. The aim of this study is to present a highly sensitive and convenient spectrofluorometric method using an internal standard for the determination of the amount of PpIX produced by ALA in the various tumor and nomnal cells.

\section{Experimental Section}

Chemicals. Protoporphyrin IX (PpLX), 5-aminolevulinic acid (ALA), trypsin/ethylenediamine-tetraacetic acid and acridine were purchased from the Sigma Chemical Co. (St. Louis, U.S.A.) and were used without further purification.

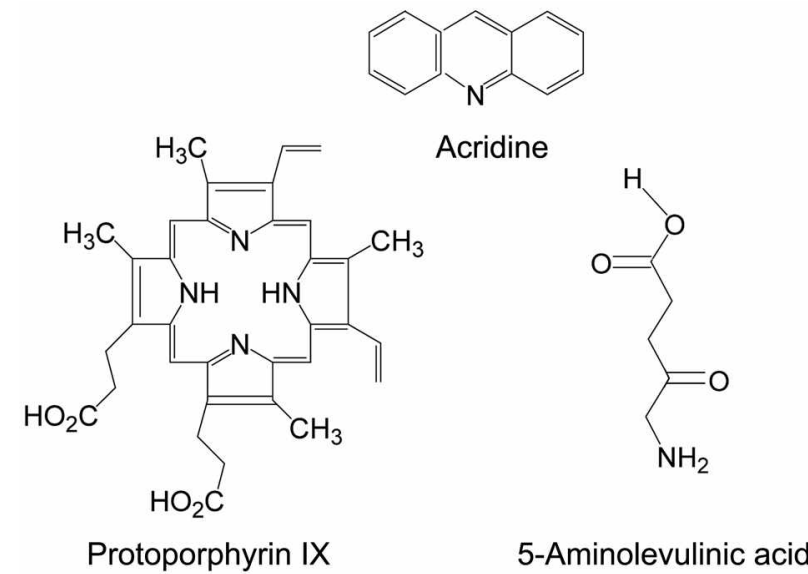

The other chemicals were of reagent grade from the Aldrich Chemical Co. and were used as recejved.

The culture medium (Dulbecco's modifjed Eagle Medium [DMEM], Roswel] Park Memorial Institute [RPMI] I640 medium), trypsin/ethylenediamine-tetraacetic acid (EDTA) and fetal bovine serum (FBS) were obtained by Biowhittaker (MD, U.S.A.)

Cell Lines and Culure Conditions. ALA-stock solution of $30 \mathrm{mM}$ was made and further diluted to $0.00 \mathrm{I}, 0.0 \mathrm{I}, 0 . \mathrm{I}, \mathrm{I}$ and $2 \mathrm{mM}$ in serum-free media immediately before being taken for the experiments. A431 cell, an epidermal squamous cell carcinoma cell line, was obtained from Korean cell line bank (KCLB No. 80005), and TXM13, a malignant melanoma cell line (KCLB No. 80029) was used. HaCaT, an immortalized epidermal keratinocyte cell line, was given by Dr. Rosemarie Steubing from Germany and human dermal fibroblast was obtained from normal human foreskin. A431, HaCaT, and fibroblast were subcultured in Dulbecco's modified Eagle Medium (Bio-whittaker, Walkersville Inc., MD, U.S.A.) containing $10 \%$ fetal bovine serum (FBS). TXM13 were subcultured in Roswell Park Memorial Institute 1640 medium containing 10\% FBS (Bio-whittaker, Walkersville Inc., MD, U.S.A.). All of the media contained 100 units $/ \mathrm{ml}$ penicillin and $10 \mathrm{ug} / \mathrm{mL}$ streptomycin. ${ }^{11}$ The cells were grown and incubated in $75 \mathrm{~cm}^{2}$ flask (Falcon, $\mathrm{NJ}$, USA) at $37^{\circ} \mathrm{C}$ in a humidified atmosphere containing $5 \%$ $\mathrm{CO}_{2}$, and subcultured two times per week. 
Incubation of Cells with ALA. For all cell lines, approximately $1 \times 10^{6}$ cells were seeded into $10 \mathrm{~cm}^{2}$ dishes (Falcon), cultured for 48 hours. Subsequently, the cells were washed twice with serum-free culture medium, and incubated in serum-free culture medium containing different concentration of ALA for 4 hours. Exposure to light was avoided during incubation with ALA.

Fluorescence Microscopy. The cells were seeded in cover slips, cultured for 24 hours, and then treated with serum-free medium containing $1 \mathrm{mM}$ ALA for 4 hours. After washing the samples with ice-cold phosphate buffered saline (PBS) three times, 4,6-diamidino-2-phenylindole (DAPI) mounting medium (Vector Lab. CA, U.S.A.) was applied to the cover slips, and inverted on a slide. For detection of fluorescence, the microscope was equipped with a $390-440$ $\mathrm{nm}$ band pass excitation filter, a $470 \mathrm{~nm}$ dichroic beam splitter, and a $610 \mathrm{~nm}$ long-pass filter. For detection of DAPI fluorescence, the microscope was equipped with a 330-380 $\mathrm{nm}$ band pass excitation filter, a $400 \mathrm{~nm}$ dichroic beam splitter, and a $420 \mathrm{~nm}$ long-pass filter.

Measurement of Cellular PpLX Fluorescence. After ALA treatment, the cells were washed twice with PBS and brought into a solution containing $1 \mathrm{M} \mathrm{HClO}_{4}$ in $50 \%$ methanol by scraping with a cell scraper. ${ }^{7}$ After $5 \mathrm{~min}$ incubation, the cell debris was removed by centrifugation $(13,000 \mathrm{rpm} / \mathrm{min}, 10 \mathrm{~min})$, and the supenatant was collected into new tubes without light exposure. This solution was used for the preparation of the aqueous PpLX. All of the aqueous solutions were prepared with quadruply distilled water, which was obtained by passing the distilled water through Banstead (U.S.A.) Nanopure II deionization system. PpIX stock solution was prepared by dissolving 10 $\mathrm{mg}$ of $\mathrm{PpIX}$ in $\mathrm{I} \mathrm{M} \mathrm{HClO}_{4}$ aqueous methanolic solution. Acridine solution $\left(8.4 \times 10^{-6} \mathrm{M}\right)$ was prepared using the same acidic aqueous methanolic mixture solution. UV/Vis absorption spectra were taken using a Uvikon, mode] 943 spectrophotometer with a $1.0 \mathrm{~nm}$ spectral bandwidth. The steady-state fluorescence emission spectra were obtained on a varian Cary Eclipse spectrofluorometer with $10 \mathrm{~nm}$ slits at room temperature.

\section{Results and Discussion}

To investigate the conversion of ALA into $\mathrm{PpLX}$ in the biosynthetic pathway of heme, we selected normal cell lines such as keratinocyte ( $\mathrm{HaCaT}$ ) and fibroblast as well as cancer cell lines such as squmaous cell carcinoma (A431) and melanoma (TXM13). The cells were treated with serumfree culture medium containing I mM ALA for 4 hours, and washed with PBS again. The cells prepared were then observed using fluorescence microscopy. As shown in Figure 1 , all of the cells emitted red light fluorescence, accumulating in the cytoplasm in each cells. However, their quantitative intensity could not be determined by the fluorescence microscopic results. To determine the fluorescence intensity produced, the cells were treated with serum-free culture medium containing $1 \mathrm{mM}$ ALA and brought into a
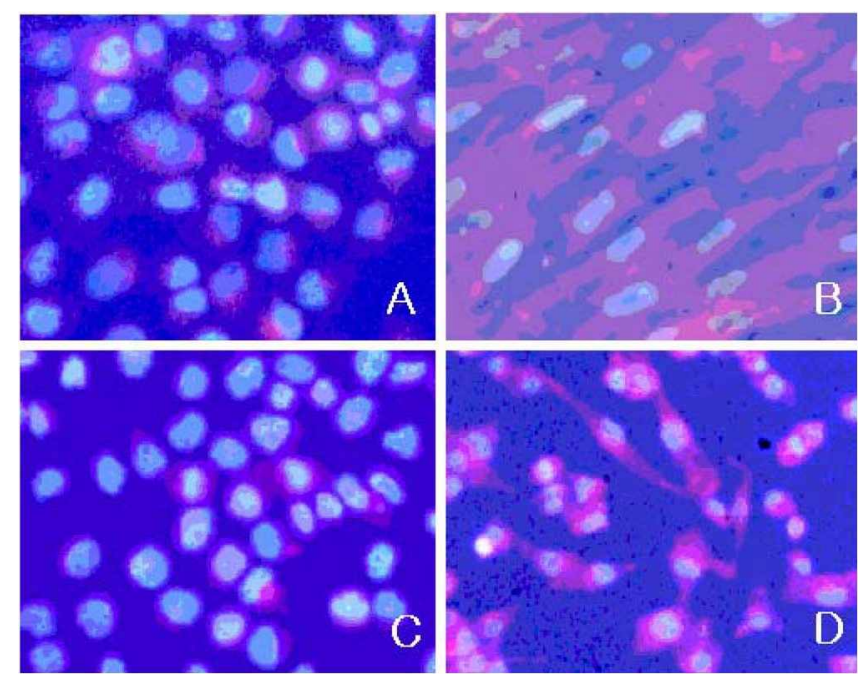

Figure 1. Protoporphyrin IX fluorescence was expressed in the cytoplasm of various cells [HaCaT cell (A), fibroblast (B), A431 (C), TXM13 (D)] related to skin after incubation of seruın-frec culture mediuın containing $1 \mathrm{mM} \Lambda \mathrm{L} A$ for 4 hours.

solution containing $1 \mathrm{M} \mathrm{HClO}_{4}$ in $50 \%$ methanol-water mixture solution. To determine the excitation wavelength for the measurement the fluorescence spectra of $\mathrm{PpIX}$, the absorption spectrum of $2.8 \times 10^{-5}$ M PpIX in methanolwater mixture solution $(50 \% \mathrm{v} / \mathrm{v})$ containing $\mathrm{I} \mathrm{M} \mathrm{HClO}_{4}$ was measured. The absorption spectrum revealed very sharp absorption maximum peak at the $408 \mathrm{~nm}$ and the molar extinction coefficient of the compound was determined to be $2.7 \times 10^{4} \mathrm{M}^{-1} \mathrm{~cm}^{-1}$ in the solvent. Therefore, we measured the fluorescence spectra of $\mathrm{PpIX}$ at the $408 \mathrm{~nm}$ as the excitation wavelength. Figure 2 shows that the fluorescence spectra of the A43I cell treated with ALA in methanol-water mixture solution containing $1 \mathrm{M} \mathrm{HClO}_{4}$ typically. The spectra were obtained in the range of $573 \mathrm{~nm}$ to $800 \mathrm{~nm}$ and appeared two emission maximum peaks at $606 \mathrm{~nm}$ and 663 $\mathrm{nm}$ regardless of the excitation wavelength. The fluorescence spectroscopic properties are quite similar to that of commercial PpIX itself in methanol-water mixture solution $(50 \% \mathrm{v} / \mathrm{v})$ containing $\mathrm{I} \mathrm{M} \mathrm{HClO}_{4}$. This is the evidence that ALA was converted into PpIX in cells. However, both of the area and height of the peak at maximum wavelength in the fluorescence spectrum varied with every measurement, although the same sample was measured. It means that the fluorescence intensity of the sample could vary in height and area depending on the instrumental conditions. To avoid this problem, it is necessary to use an intenial standard and acridine was the choice of the copmpound.

Acridine dissolves well in methanol-water mixture solution containing $1 \mathrm{M} \mathrm{HClO}_{4}$ and absorbs the light of 408 $\mathrm{nm}$. Figure 3 shows the fluorescence spectra of the various concentrations of acridine in methanol-water mixture solution $(50 \% \mathrm{v} / \mathrm{v})$ containing $1 \mathrm{M} \mathrm{HClO}_{4}$. The spectra were measured in the range of $420 \mathrm{~nm}$ to $600 \mathrm{~nm}$ and had an emission maximum peak at $480 \mathrm{~nm}$. Although acridine shows fluorescence spectrum overlapped with PpIX from 


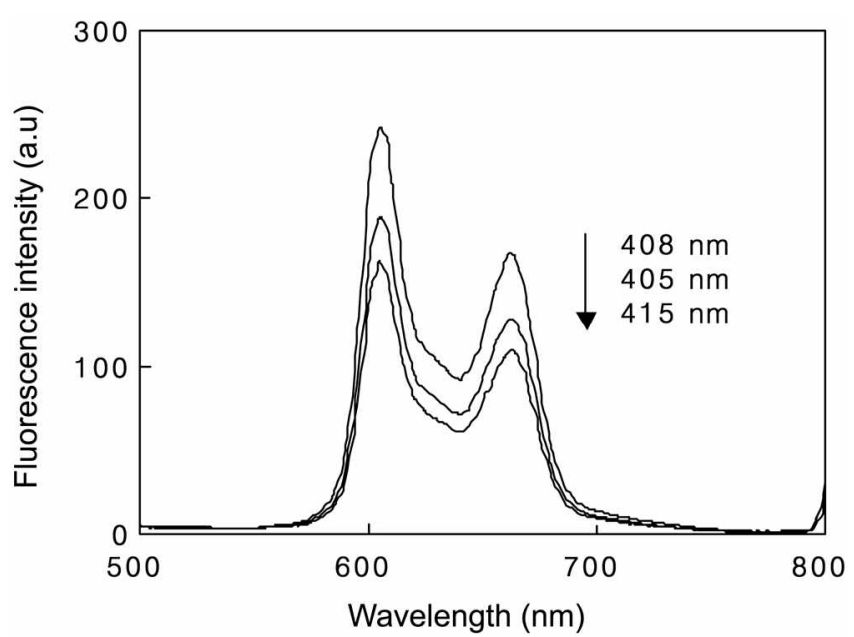

Figure 2. Fluorescence spectra of A431 cell treated with ALA in methanol-water mixture solution $(50 \% \mathrm{v} / \mathrm{v})$ containing $1 \mathrm{M} \mathrm{HClO}_{4}$ at various excitation wavelength.

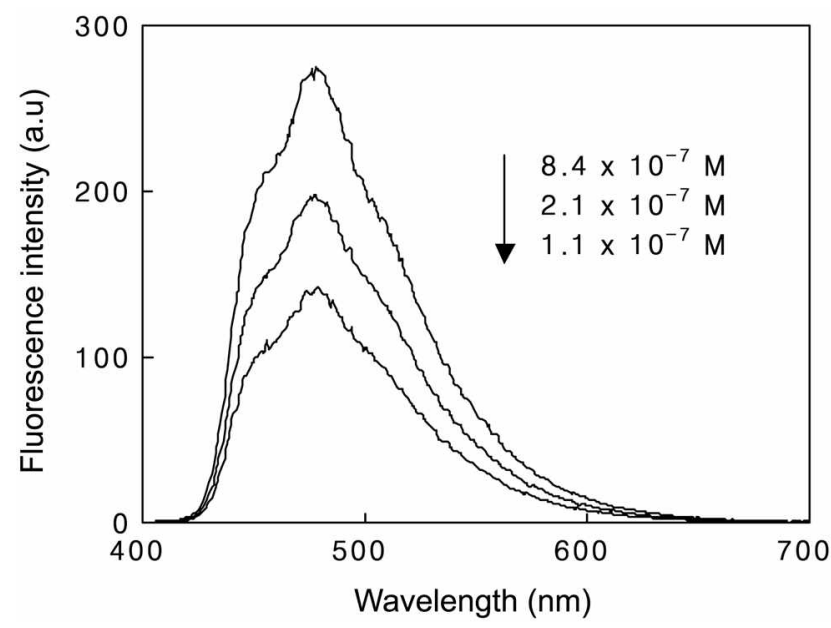

Figure 3. Fluorescence spectra (excitation at $408 \mathrm{~nm}$ ) of the various concentration of acridine in methanol-water inixture solution $(50 \% \mathrm{v} / \mathrm{v})$ containing $1 \mathrm{M} \mathrm{HClO}+$

$573 \mathrm{~nm}$ to $600 \mathrm{~nm}$ as shown in Figure 4, its effect on the spectrum is negligible, i.e. less than $2 \%$ when the concentration of acridine is $8.4 \times 10^{-6} \mathrm{M}$. The amount of PpIX produced can be determined by the measurement of the maximum peak height in the fluorescence spectrum by comparing with calibration curve. However, there might be some errors because of the variation of the peak height as mentioned above. Besides, the values of the peak hejght at maximum wavelength in the fluorescence spectrum were recorded up to about 500 arbitrary units, whereas the peak areas in fluorescence spectra were recorded up to about 60,000 as given experimental condition. It means that we set up a reliable and accurate procedure for the detemination of PpIX produced in various cells treated with ALA using acridine as interanal standard.

In order to examine the chemical stability of the PpIX with acridine in methanol-water mixture solution containing

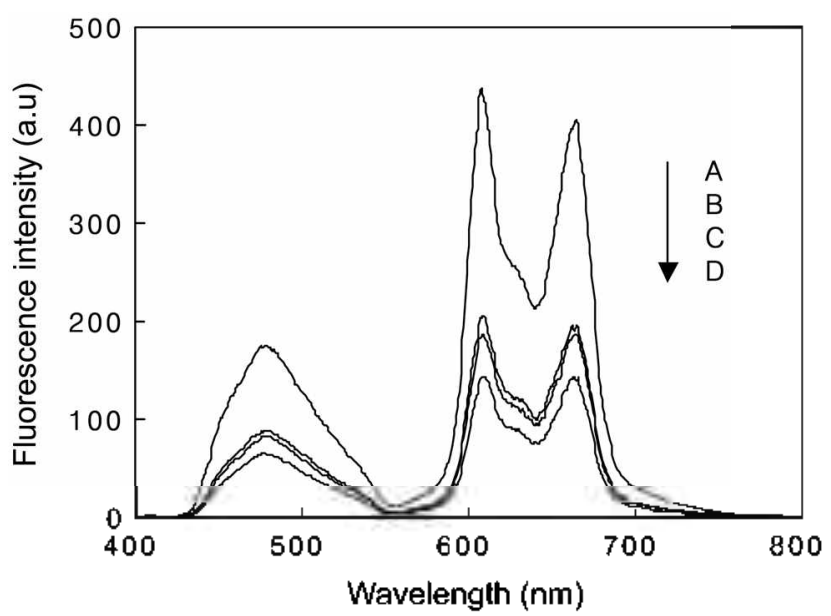

Figure 4. Fluorescence spectra (excitation at $408 \mathrm{~nm}$ ) of $8.4 \times 10^{-8}$ $\mathrm{M}$ protoporphyrin IX $(2 \mathrm{~mL})$ inixed with $50 \mu \mathrm{L}$ of $8.4 \times 10^{-6} \mathrm{M}$ acridine in methanol-water mixture solution $(50 \% \mathrm{v} / \mathrm{v})$ containing $1 \mathrm{M} \mathrm{HClO}_{4}$ in the various storage time of the sample: $\mathrm{A}$; after 1 hour, B; after 24 hours, C; after 30 hours, D after 48 hours.

$1 \mathrm{M} \mathrm{HClO}_{4}, 50 \mu \mathrm{L}$ of $8.4 \times 10^{-6} \mathrm{M}$ acridine was added into $2 \mathrm{~mL}$ of $8.4 \times 10^{-8} \mathrm{M} \mathrm{PpDX}$ and the fluorescence spectra were recorded as a function of storage time of the sample. As shown in Figure 4, the fluorescence intensity of the both compounds diminished with increasing the storage time of the sample. However, the ratio between the fluorescence peak area of PpIX and acridine remained unchanged $(2.31 \pm$ 0.02 ) regardless of the storage time of the sample. It indicates that acridine does not react with PpIX in methanol-water mixture solution containing $\mathrm{I} \mathrm{M} \mathrm{HClO} 4$ under given experimental conditions. Moreover, the fluorescence spectra of the PpIX were obtained very well, although their concentrations are very low (about $10^{-8} \mathrm{M}$ ). It means that this spectrofluorometric method for the determination of the amount of ALA induced PpIX is a highly sensitive, accurate, and reliable method. The results support that acridine is a good intemal standard compound for quantitative measurement of PpIX induced from exogenous ALA in PDT.

In conclusion, HaCaT, fibroblast, A43I and TXM13 cells treated with ALA emit red light fluorescence with absorption maximum at $408 \mathrm{~nm}$ in methanol-water mixture solution containing $\mathrm{I} \mathrm{M} \mathrm{HClO}_{4}$ indicating the conversion of exogenous ALA into PpIX. The fluorescence spectrum of PpIX was measured in the range of $573 \mathrm{~nm}$ to $800 \mathrm{~nm}$, whereas that of acridine was recorded in the range of $420 \mathrm{~mm}$ to $600 \mathrm{~nm}$. Acridine did not react with PpIX and was found to be a good internal standard for a highly sensitive, accurate, and reliable spectrofluorometric method to determine PpIX in the PDT.

Acknowledgment. This work was supported by grant No. RTI04-03-03 from the Regional Technology Innovation Program of the Ministry of Commerce, Industry and Energy (MOCIE). 


\section{References}

1. Otake, M.; Nishiwaki, M.; Kobayashi, Y.; Baba, S.; Kohno, E.; Kawasaki, T.; Fujise, Y.; Nakamura, H. British J. Cancer 2003, 89,730 .

2. Kenedy, J.; Potter, R.; Pross, G. Photochem. Photobiol. B 1990, 6 , 143.

3. Berlin, N. I.; Neuberger, A.; Scott, J. J. Biochemistry 1956, 64 . 80.

4. Kloeck, J.; Akkermans, W; Beijersbergen van Henegouwer, G. M. J. Photochem. Photobiol. 1998, 67, 150.

5. Zensen, V.; Zankl, H. Cancer Letters 2003, 202, 35.

6. Georgakoudi, J.; Forster, T. H. Photochent. Photobiol. 1998, 67.
612.

7. Gaullier, J. M.; Berg, K.; Peng, Q.; Anholt, H.; Selbo, P. K.; Ma, L. W.; Moan, J. Cancer Research 1997, 57, 1481.

8. Gerscher, S.; Connelly, J. P.; Griffiths, J.; Brown, S. B.; MacRobert, A. J.; Wong, G.; Rhodes, L. E. Photochem. Photobiol. $2000,72,569$.

9. Xiang. W.; Weingandt. H.; Liessmann, F.; Klein. S.; Stepp. H.; Baumgartner, R.; Hillemanns, P. Photochen. Photobiol. 2001, 74, 617.

10. Lakowicz, J. R. Principles of Fhorescence Spectroscopy; Plenum Press: New York, USA, 1983;p 19.

11. Casas, A.; Fukuda, H.; Venosa, Gi D.; Balle, A. British Joumal of Cancer 2001, 85, 279. 